\title{
SPONTANEOUS HEPATIC RUPTURE AFTER REVASCULARIZATION DURING TRANSPLANTATION
}

Albajar Bobes, A.; López Morales, M.; Casado Salcedo, M.; Abdallah, N.; B.; Azcoitia, J.; García Fernández J.; Hospital Universitario Puerta de Hierro, Majadahonda, Madrid, España.

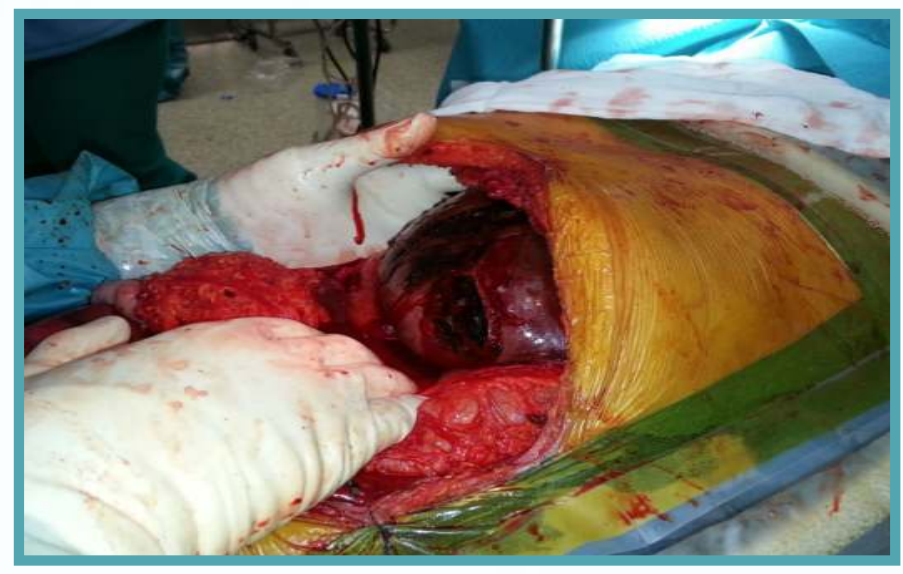

\section{INTRODUCTION:}

Spontaneous hepatic rupture has been describe before in association with some conditions but there is only few cases in which a spontaneuos liver rupture during transplantation has been reported(I). We present one of these case, requiring total hepatectomy and portocaval shunt, followed by retransplatation

\section{CASE REPORT:}

A 65 year-old man HVC positive with chronic hepatopathy CHILD B,MELD I2-I5, was admitted for an elective liver transplantation. The donor was a woman with a history of Chagas disease with normal liver function tests.After completing the caval and portal anastomosis, the liver was revascularized.Within minutes the liver developed multiple large subcapsular haematomas that spontaneously ruptured leading to a massive uncontrollable bleeding.Despite the multiple transfusions and all the efforts to stop the bleeding the liver continue to rupture, forcing the surgeons to perform an hepatectomy of the implanted liver and a end-to-side portocaval anastomosis. The patient was taken to the intensive care unit and was retransplanted 14 hours later. Coagulopathy, haemodinamic instability, renal and respiratory failure and pancytopenia complicated the postoperative period.The patient was discharge from the ICU two months later.
Spontaneous hepatic rupture is rare. The exact aetiology is not well understood.(I)(2). In our case no syndrome was found in the history of the patients nor the pathological studies of the implant. Because of this rare condition, no single institution has acumulated enough experience to be able to make recommendations about treatment(2).In an unstable patient with rupture of the

liver, operation is ussually neccesary. In some cases perihepatic packing, segmentectomy or hemihepatectomy are enough.(2)In others the only possible treatment is total hepatectomy followed by liver trasplantation. Over the last years, the intraoperative technique of venovenous bypass is become more selective. However this technique has been use in most of the cases during the anaepathic phase if the trasplantation was carried out in two phases(3). Our patient was not placed in bypass, with a 14 hour time of portocaval shunt. The most common complications that could occur because of the portocaval anastomosis are those related with venous hypertension.

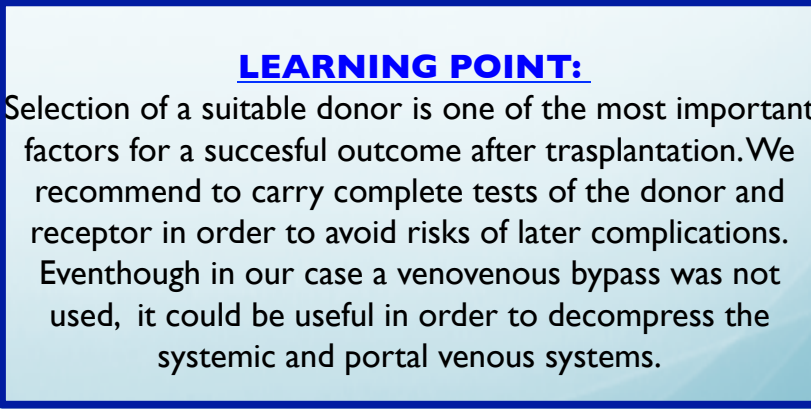

1.Mistry,B.;Spontaneous rupture of the liver upon revascularization during transplantation.Transplantation 2000;69:22 I 4-22 I8.

2.Mascarenhas, R.Spontaneuos hepatic rupture: a report of five cases.HPB 2002;4(4): I67-I 70.

3.Sanabria,R.; Total hepatectomy and liver transplantation as a two-stage procedure for fulminant hepatic failure:A safe procedure in exceptional circumstances. World J Hepatol. 2016,8(4):226-230. 